\title{
TU/e Emonowe

\section{Modeling of confined and unconfined laminar premixed flames on slit and tube burners}

\section{Citation for published version (APA):}

Mallens, R. M. M., Lange, de, H. C., Ven, van de, C. J. H., \& Goey, de, L. P. H. (1995). Modeling of confined and unconfined laminar premixed flames on slit and tube burners. Combustion Science and Technology, 107(4-6), 387-401. https://doi.org/10.1080/00102209508907812

DOI:

10.1080/00102209508907812

Document status and date:

Published: 01/01/1995

\section{Document Version:}

Publisher's PDF, also known as Version of Record (includes final page, issue and volume numbers)

\section{Please check the document version of this publication:}

- A submitted manuscript is the version of the article upon submission and before peer-review. There can be important differences between the submitted version and the official published version of record. People interested in the research are advised to contact the author for the final version of the publication, or visit the $\mathrm{DOI}$ to the publisher's website.

- The final author version and the galley proof are versions of the publication after peer review.

- The final published version features the final layout of the paper including the volume, issue and page numbers.

Link to publication

\section{General rights}

Copyright and moral rights for the publications made accessible in the public portal are retained by the authors and/or other copyright owners and it is a condition of accessing publications that users recognise and abide by the legal requirements associated with these rights.

- Users may download and print one copy of any publication from the public portal for the purpose of private study or research.

- You may not further distribute the material or use it for any profit-making activity or commercial gain

- You may freely distribute the URL identifying the publication in the public portal.

If the publication is distributed under the terms of Article 25fa of the Dutch Copyright Act, indicated by the "Taverne" license above, please follow below link for the End User Agreement:

www.tue.nl/taverne

Take down policy

If you believe that this document breaches copyright please contact us at:

openaccess@tue.nl

providing details and we will investigate your claim. 


\title{
Modeling of Confined and Unconfined Laminar Premixed Flames on Slit and Tube Burners
}

\author{
R. M. M. MALLENS, H. C. de LANGE, C. H. J. van de VEN and L. P. H. de GOEY \\ Eindhoven University of Technology, Faculty of Mechanical Engineering \\ (WOC), PO Box 513, 5600 MB Eindhoven, The Netherlands
}

(Received November 18, 1994; in final form May 23, 1995)

\begin{abstract}
A model is presented for laminar premixed Bunsen flames on slit and cylindrical burners burning in a surrounding atmosphere. A comparison between modeling and experimental results shows that the model can reproduce the experimental results within $10 \%$ accuracy. The influence of a surrounding atmosphere and burner curvature on the flame shape, flow field and mass transport in 2D laminar premixed Bunsen flames is also investigated. It is found that flames on cylindrical burners confined between similar flames have a smaller flame length and flame tip curvature than fiames on slit burners with comparable dimensions. These effects are caused by the larger available expansion space (in radial direction) for the cylindrical flames. Furthermore, it is shown that the flames in a surrounding atmosphere are less curved than flames confined between other flames; the curvature of the tip is also smaller. These effects are explained by the fact that the confining flames push the mass flow and the flame front towards the central axis. This in turn results in differences in flame length. The investigation gives more quantitative insight in the effect of a surrounding atmosphere and burner geometry on the transport of mass in premixed laminar flames.
\end{abstract}

Key Words: Burner geometry, confinement, 2D numerical modeling, one-step chemistry, laminar flames

\section{INTRODUCTION}

Experimental studies of Bunsen flames on slit and cylindrical burners with a surrounding atmosphere have been performed by many authors, e.g. Echekki (1990), Hertzberg (1990), Lewis (1961) and Wagner (1985). These studies mainly focus on the effects of the surrounding atmosphere on the blow-off or flash-back behavior and on the effects of curvature in the flame tip. The results show that these effects are related to the convective and diffusive transport of heat and mass near the flame front.

Two-dimensional (2D) methane air Bunsen flames have been studied numerically by several authors. Smooke et al. (1989) and Coelho (1993) consider two-dimensional diffusion flames. A surrounding environment is incorporated by defining a fixed co-flowing air stream surrounding the fuel jet. Fukutani (1993) studied the transport of mass and energy between lean 2D premixed flames surrounded by stoichiometric flames with complex chemistry. De Lange (1992-94) presented a numerical code for modeling the transport processes in 2D premixed laminar methane/air flames with one-step chemistry using adaptive local grid refinement techniques. This model will be used as starting point in this study. This model was only suited for flames on multiple-slit burners. Mathematically this means that one flame is confined between two symmetry boundaries and that it is not affected by the surrounding atmosphere. 
The model has been extended to the modeling of flames burning in a surrounding atmosphere of cold air with gravity in order to study the effects of a surrounding atmosphere on global flame properties and transport processes in laminar premixed flames. The surrounding atmosphere is not incorporated by means of a coflowing air stream with a given velocity but by means of 'free' in/outstream boundaries. Furthermore, a version of the model suited for the modeling of flames on cylindrical burners with co-axial slits has been developed. The model is essentially two-dimensional in both cases. Let us introduce a curved annular burner with a radius of curvature $R_{0}$ (Fig. 1). Note that a slit burner coincides with $R_{0} \rightarrow \infty$ and that a cylindrical burner coincides with $R_{0}=0$. In this paper we present experimental and modeling results of flames on rectangular slit burners $\left(R_{0} \rightarrow \infty\right)$ and cylindrical (tube) burners $\left(R_{0}=0\right)$. Flames burning in a cold surrounding atmosphere and flames confined between similar flames will be considered. The four different situations are presented schematically in Figure 2 and the numerical computation domains are shown in Figure 3. It is assumed that the velocity profile near the exit of the burner is given by:

$$
v(x)=V_{\max }\left\{1-\left(\frac{x}{b}\right)^{2}\right\}
$$

for all cases. In Equation (1), $v$ represents the velocity in $y$ direction and $V_{\max }$ the maximum velocity in the burner port. Note that the confined case with $R_{0}=0$ (Fig. 2a) does not have an experimental equivalent, due to the fact that the interface between two coaxial flames at $x=B$ is not an exact symmetry boundary. The chosen domain and boundary conditions are, however, introduced to investigate the effects of $R_{0}$ on the mass transport in flames surrounded by similar flames.

The flow field and chemical model are discussed in the following section. Then numerical results for a Bunsen flame on a $4.2 \mathrm{~mm}$ single-slit burner $\left(R_{0} \rightarrow \infty\right.$ and $b=2.1 \mathrm{~mm})$ and a Bunsen flame on a $9.6 \mathrm{~mm}$ tube burner $\left(R_{0}=0 ; b=4.8 \mathrm{~mm}\right)$ will be discussed. The modeled velocity field near and within the flame cone on the single-slit

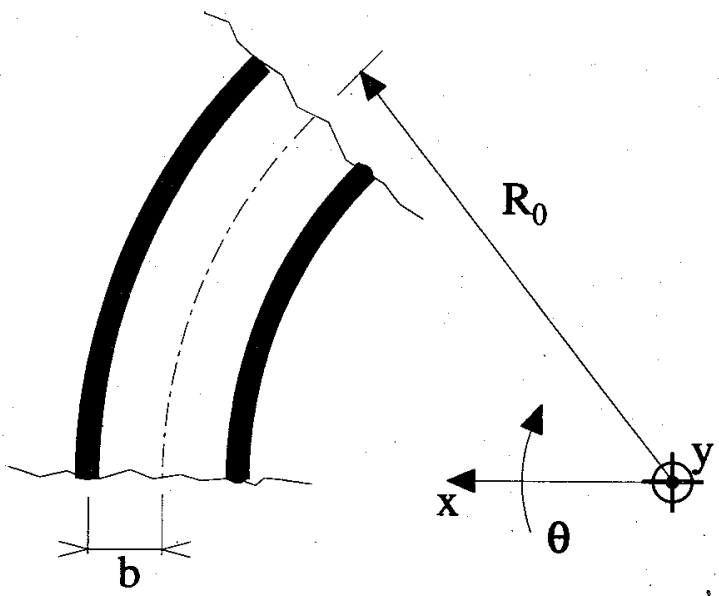

FIGURE 1 The burner geometry. 


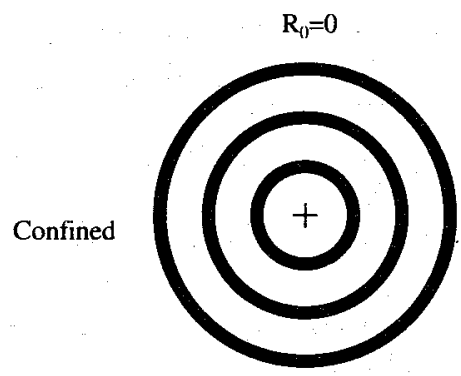

(a)

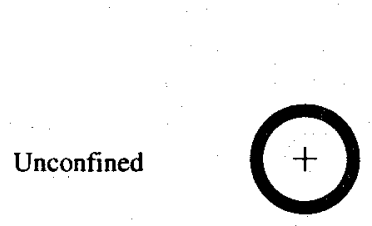

(c)

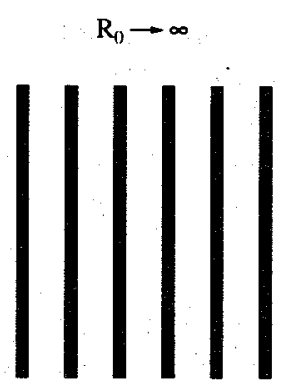

(b)

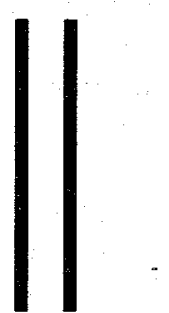

(d)

FIGURE 2 The four different burner systems; cylindrical anulus burner (a), multiple-slit burner (b), tube burner in environment (c) and single-slit burner in environment.

burner will be compared with Laser Doppler Velocimetry (LDV) measurements. The modeled flame shape of the flame on the tube burner will also be compared with its experimental equivalent. Typical flow field characteristics reported by other references (Echekki (1990), Hertzberg (1990), Lewis (1961), Mungal (1994)) will be considered as well.

Finally, the effect of $R_{0}$ on Bunsen flames confined between similar flames is investigated by comparing differences in flame shape and mass flow through the tip for the cases with $R_{0}=0$ and $R_{0} \rightarrow \infty$. The effect of a surrounding atmosphere on the flame shape and the mass flux through the tip is also studied.

\section{COMBUSTION EQUATIONS AND CHEMICAL MODEL}

The combustion equations, boundary conditions, chemical model, physical parameters and numerical method are presented in this section.

\section{Conservation Equations and Boundary Conditions}

The 2D stationary flow field is modeled with a vorticity-stream function formulation (de Lange, 1994) including gravity. The vorticity $\omega$ and the stream function $\varphi$ are defined according to de Lange $(1992,1994)$ for $R_{0} \rightarrow \infty$ and Smooke et al. (1989) for $R_{0}=0$. The equation from which the stream function is solved is also given by de Lange $(1992,1994)$ and Smooke et al. (1989). 
The conservation equations for the vorticity $\omega$, the mass fractions $Y_{i}$ and energy (in terms of the temperature $T)$ are given by Smooke et al. $(1989)$, de Lange $(1992,1994)$ and Williams (1988).

The boundary conditions at the in/outflow boundaries, the symmetry boundaries and the burner wall (shown in Fig. 3) for the flow velocity $\mathbf{v}=(u, v)$, de temperature $T$ and mass fractions $Y_{i}$ will be treated first; the formulation for $\varphi$ and $\omega$ will be treated subsequently.

At the inlet the boundary conditions are given by $u=0, T=T^{u}$ and $Y_{i}=Y_{i}^{u}$, with $T^{u}$ the unburnt gas temperature and $Y_{i}^{u}$ the mass fractions of the unburnt mixture, while $v$ is given by Equation (1). At the free in/outstream boundaries next to the burner and at $x=L_{x}$ we use $\partial \rho u / \partial y=0, T=T^{u}$ and $Y_{i}=Y_{i}^{a i r}, Y_{i}^{\text {air }}$ denoting the mass fractions of species $i$ in air. The other mass flow component $\rho v$ is found from the stream function definition. On the other in/outflow boundary $\rho u, T$ and $Y_{i}$ are calculated by assuming that their derivatives perpendicular to the boundary are equal to zero. This gives $\partial \rho u / \partial y=0, \partial T / \partial y=0, \partial Y_{i} / \partial y=0$ and $\rho v$ is determined from $\varphi$ again. At the symmetry boundaries we use $u=0, \partial \rho v / \partial x=0, \partial T / \partial x=0, \partial Y_{i} / \partial x=0$ and at the walls $u=0$, $v=0, T=T^{u}, \partial_{i} Y_{i} / \partial y=0$ (for walls along the $x$-axis) and $\partial Y_{i} / \partial x=0$ (for walls along the $y$-axis).

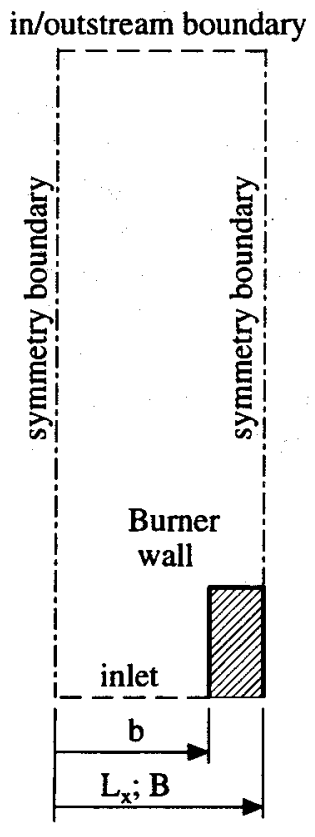

(a)

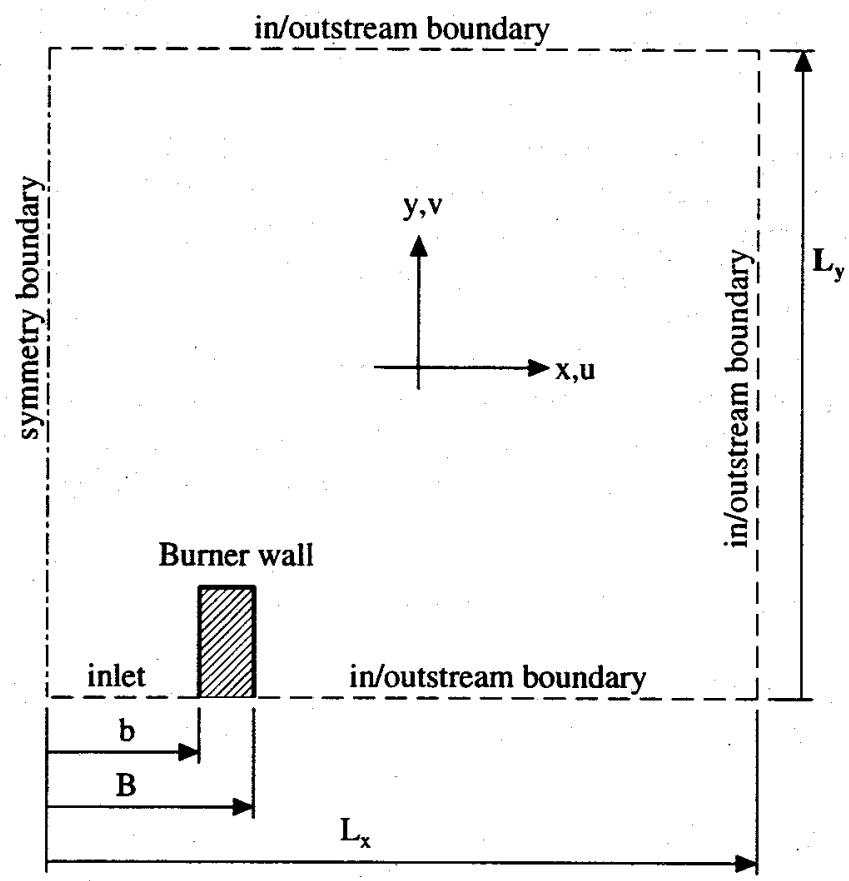

(b)

FIGURE 3 The computational domain used for modeling confined (a) and unconfined flames (b), For axisymmetrical cases the radial coordinate is in the $x$-direction. 
The boundary condition for the stream function at the free in/outstream boundaries is determined by assuming that the second-order derivative perpendicular to the boundary is equal to zero: $\partial^{2} \varphi / \partial y^{2}=0$, which corresponds to $\partial \rho u / \partial y=0$ at these boundaries. The formulation for $\varphi$ on the other boundaries is found by integrating the perpendicular component of the mass flux vector over the boundary contour. This means that the values of $\varphi$ on walls and symmetry boundaries are constant. Analytical integration of the parabolic mass flux profile $\rho v(x)$ is used to determine $\varphi$ at the inlet.

The boundary conditions for the vorticity are determined from the flow-field near the boundary and the definition of $\omega$. Note that this reduces to $\omega=0$ on symmetry walls and to $\omega=\partial v / \partial x$ or $\omega=-\partial u / \partial y$ for walls along the $y$ axis and $x$ axis, respectively.

\section{Chemical Model and Physical Parameters}

As chemical model, a one-step irreversible reaction fuel + oxygen $\rightarrow$ products is used with an Arrhenius-type source term for the fuel consumption rate:

$$
\dot{\rho}_{f u}\left(T, \rho, Y_{f u}, Y_{o x}\right)=-A \rho^{\alpha+\beta}\left(Y_{f u}\right)^{\alpha}\left(Y_{o x}\right)^{\beta} e^{-T_{a} / T} .
$$

Here $A, \alpha, \beta$ and $T_{a}$ are reaction rate parameters $\left(\alpha=2.8, \beta=1.2, A=2.6 \cdot 10^{15}\right.$ $\left[\mathrm{kgm}^{-3}\right]^{-3} \mathrm{~s}^{-1}$ and $\left.T_{a}=16900 \mathrm{~K}\right)$ and $Y_{i}(i=f u, o x, p r)$ are the mass fractions of fuel, oxidizer and products, respectively.

The rate Equation (2) and the reaction rate parameters are determined in such a way that the dependence of the burning velocity on temperature, computed for flat burnerstabilized methane/air flames, deviates no more that $10 \%$ from experimental results of Andrews (1972), Kaskan (1967) and van Maaren et al. (1994) in the range of equivalence ratios $0.8 \leqslant \phi \leqslant 1.2$ (see de Lange (1992) for more details). The method is similar to that of Coffee et al. (1984) who determined $\phi$-dependent one-step reaction parameters, using detailed numerical chemistry data for comparison.

It is important that the model computes accurate flame temperatures, due to the sensitivity of the flame properties on the local temperature. The combustion enthalpy $\Delta h$ is therefore determined in such a way that the correct adiabatic flame temperature is found as a function of equivalence ratio $\phi$ (de Lange $(1992,1993)$ ). The calculation of the specific heat $c_{p}$, the thermal conductivity $\lambda$, the dynamic viscosity $\mu$, andthe binary diffusion coefficients $D_{i m}$ of the species $i$ in bulk $m$ is given by de Lange $(1992,1993)$.

\section{Numerical Method}

The numerical methods used to solve the problem are elaborately discussed in de Lange (1994). The conservative finite-volume method of Thiart (1990) is applied to discretise the conservation equations. The discretisation is performed on adaptive, locally-refined, non-staggered grids and the linearised set of algebraic equations is solved using the ADI method.

\section{RESULTS FOR UNCONFINED FLAMES AT $R_{0}=0$ AND $R_{0} \rightarrow \infty$}

A qualitative study of de Lange (1993) showed that the model predicts the flame length and flame shape of confined premixed methane/air flames on slit burners within $10 \%$ 
accuracy. In this section we present numerical results and a more quantitative validation of the model applied on atmospheric methane/air flames $\left(T^{u}=298 \mathrm{~K}, \phi=1\right)$ in an open atmosphere $\left(Y_{f u}^{a i r}=0, Y_{o x}^{a i r}=0.232\right)$. We consider a flame on a slit $\left(R_{0} \rightarrow \infty\right)$ and a flame on a tube $\left(R_{0}=0\right)$ burner. The $R_{0}=0$ case is treated first. The flame shape and the flow field produced by the model is compared qualitatively with the visible flame front and flow field on a direct photograph including particle tracks (Fig. 4). For the $R_{0} \rightarrow \infty$ case, presented subsequently, we compare the computed profiles of the vertical velocity component $v$ with Laser-Doppler Velocimetry (LDV) measurements.

The computational domain is given in Figure $3 \mathrm{~b}$. The magnitude of the domain, the maximum inlet velocity $V_{\max }$, the equivalence ratio $\phi$ and the base grid spacing $\Delta$ are listed in Table I for $R_{0} \rightarrow \infty$ and $R_{0}=0$. The calculations are performed on a coarse base grid with three adaptive refinement layers.

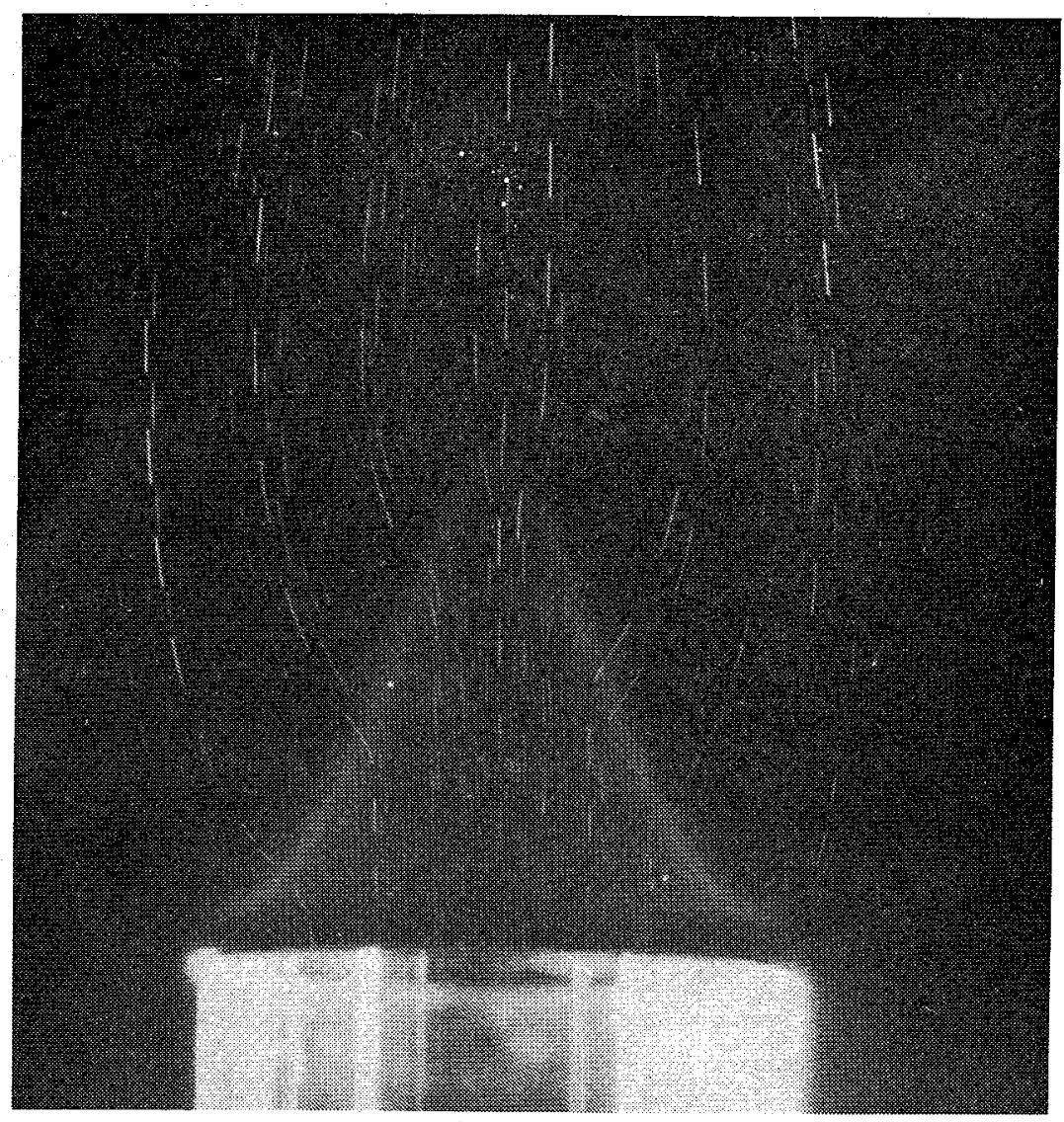

FIGURE 4 A direct photograph of a methane/air flame $(\phi=0.9)$ on a cylindrical Bunsen burner. The velocity profile at the burner exit is parabolic with a maximum velocity of $0.9 \mathrm{~m} / \mathrm{s}$. 
TABLE I

The domain measures for the flames discussed in section 3

\begin{tabular}{lrr}
\hline$R_{0}$ & $\infty$ & \multicolumn{1}{c}{0} \\
\hline$b[\mathrm{~mm}]$ & 2.1 & 4.8 \\
$B[\mathrm{~mm}]$ & 4.8 & 6.0 \\
$L_{x}[\mathrm{~mm}]$ & 15.0 & 24.0 \\
$L_{y}[\mathrm{~mm}]$ & 15.0 & 30.0 \\
$V_{\text {max }}[\mathrm{m} / \mathrm{s}]$ & 1.1 & 0.9 \\
$\phi[-]$ & 1.0 & 0.9 \\
$\Delta$ & 0.3 & 0.3 \\
\hline
\end{tabular}

Results for $R_{o}=0$

The computed grid with three refinement levels is presented in Figure 5. The contours of the stream function and temperature are given in Figure 6. A qualitative comparison of the stream lines given by the model and the particle tracks visible on the photograph shows that the flow field near the flame cone is well reproduced by the code. The stream lines above the experimental flame $(y \geqslant 0.01 \mathrm{~m})$ bend back towards the central axis due to acceleration of the hot combustion products by gravitational forces between the hot combustion products and the cold gases in the surrounding atmosphere. This effect is

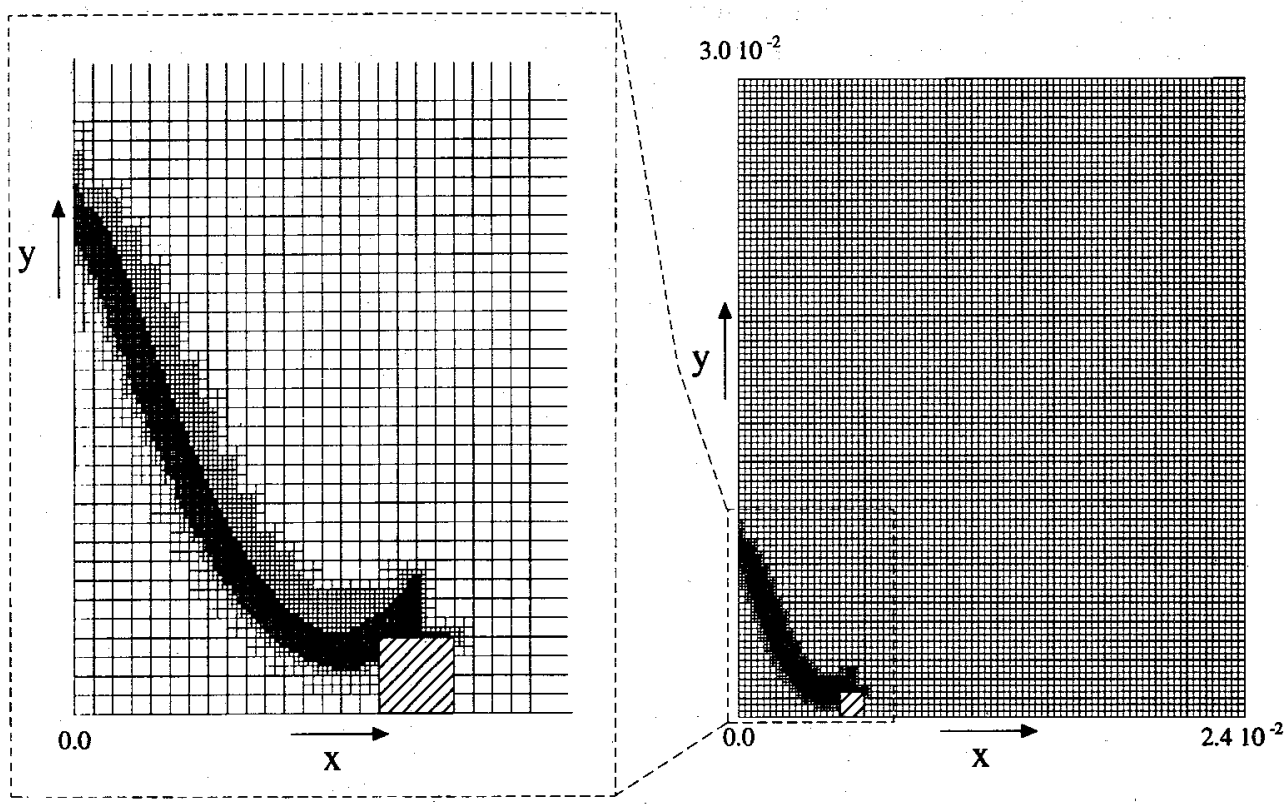

FIGURE 5 Computational grid for the modeled equivalent of Figure 4 (case c). The domain used for the calculation is given by Figure $3 \mathrm{~b}$. 

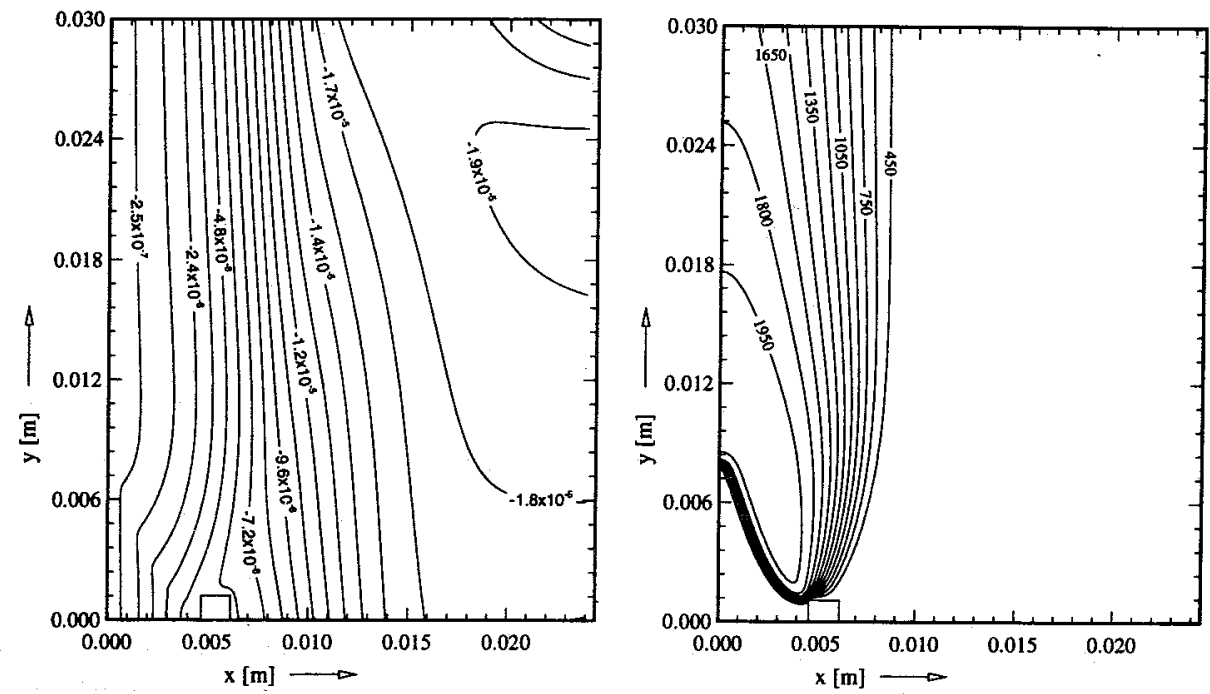

FIGURE 6 Contours of stream function (left) and temperature (right) for case $\mathrm{c} ; R_{0}=0$. The numbers in the contour lines denote the contour value in $[\mathrm{kg} / \mathrm{ms}]$ and $[\mathrm{K}]$, respectively.

also present in the modeled flow field. A detailed validation of the flow field in the near flame zone produced by the model is given in the next subsection.

The flow field in the surrounding atmosphere (at $x$ values larger than $0.007 \mathrm{~m}$ ) produced by the model cannot be validated because it is not visible on the particle track photograph. Computations with different domain sizes and grid spacings $\Delta$ did not lead to significant variations in the flow field near and inside the flame. The other flame properties such as the flame shape and temperature were not affected by the domain size and $\Delta$.

The shape of the flame is well reproduced by the model. The flame front is defined as the maximum locus of the heat release for the modeled flame and as the middle of the luminous zone for the experimental flame. The sides of the modeled flame are almost parallel to the flame front in the photograph. The deviation is largest in the tip. The length of the modeled flame is about $7.6 \mathrm{~mm}$, while the length of the experimental flame is roughly equal to $8.6 \mathrm{~mm}$. Part of the observed discrepancies (of the order of the thickness of the flame front, which is about $0.9 \mathrm{~mm}$ ) are probably caused by the differences in the flame front definitions. From the results we may conclude that the model reproduces the flame shape and the flow field near the flame well. A more quantitative validation of the model will be given in the next subsection.

\section{Results for $R_{o} \rightarrow \infty$}

The contours of stream function and temperature for the modeled flame on the $4.2 \mathrm{~mm}$ slit burner are given in Figure 7. The most striking difference with the modeled flow field for $R_{0}=0$ (see previous subsection) lies in the flow field downstream of the flame cone. The stream lines for $R_{0}=0$ converge at larger $y$ values whereas the streamlines for $R_{0} \rightarrow \infty$ do not show this behaviour; at least not inside the computational domain. 

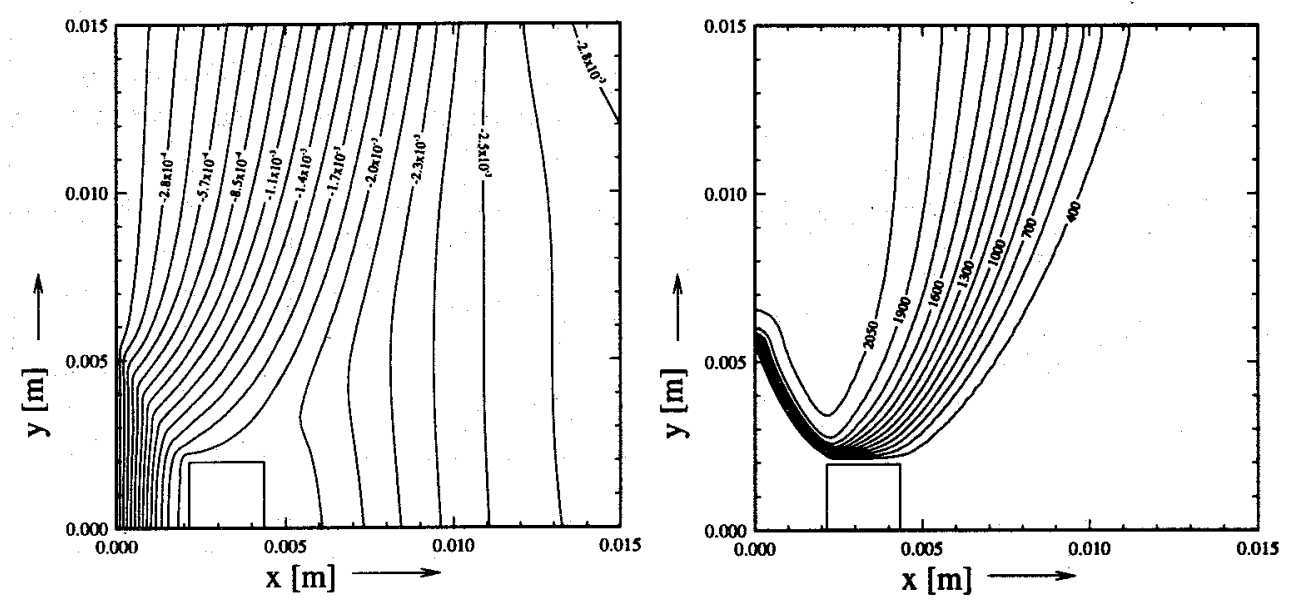

FIGURE 7 Contours of stream function (top) and temperature (bottom) for case $\mathrm{d}\left(R_{0} \rightarrow \infty\right)$. The numbers in the contour lines denote the contour value in $[\mathrm{kg} / \mathrm{s}]$ and $[\mathrm{K}]$, respectively.

Flow fields above slit burners given by Lewis (1961) also show a non-converging behaviour. This leads to the conclusion that the converging behaviour of the streamlines for $R_{0}=0$ is caused by lower velocities in the radial direction $(x)$ (also see the next section) and by the larger interface with the cold air surrounding the flame which causes larger gravitational forces on the hot flow near the symmetry axis.

The results for $v$ found with the model and LDV measurements on the slit burner $\left(R_{0} \rightarrow \infty\right)$ are given in Figure 8. The vertical velocity $v(x, y=H)$ is given as a function of $x$ for some heights $H$ above the burner rim. The shape of the profiles is well captured by the model. The values of the measured velocities differ no more than $15 \%$ from the velocities produced by the model. These differences are mainly caused by small differences in flame shape. Small variations in the flame position can lead to the observed differences because the profiles change rapidly in $y$ direction near the flame front. The differences are of the same order of magnitude as the accuracy of the measurements because LDV measurements give errors of 10-15\% (Wagner, 1985) in the flame tip region. In view of the above we may conclude that the model gives a good representation of the velocity field near the two-dimensional flame on the slit burner.

The profiles at $H=3.5 \mathrm{~mm}$ show a minimum on the central axis which is probably caused by a wake-like behaviour of the flow behind the flame tip (Mungal, 1994). This behaviour is also reported by Mungal (1994) who performed Particle Image Velocimetry measurements in cylindrical Bunsen flames. Pressure fields near and within a laminar Bunsen flame given by Poinsot (1992) show a pressure minimum behind the flame tip. This is consistent with the wake-like behaviour and the velocity minimum behind the tip. The minimum is more pronounced in the modeled profile. This could, however, be due to small differences in flame position. The minimum at the central axis is present in all modeled flames (at $R_{0}=0$ and $R_{0} \rightarrow \infty$ ).

The measured and modeled vertical velocity $v$ at the centerline $(x=0)$ both decrease with increasing $y$ in the lower part of the flame cone. The decreasing velocity is a result 


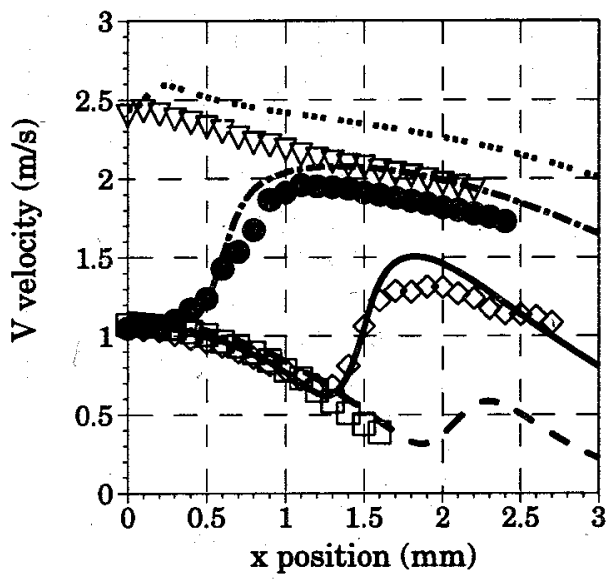

\begin{tabular}{|c||c|c|}
\hline$H(\mathrm{~mm})$ & Model: & LDV-meas.: \\
\hline \hline 0.5 & --- & $\square$ \\
\hline 1.0 & - & $\diamond$ \\
\hline 2.5 & $\cdots$ & $\bullet$ \\
\hline 3.5 & $\cdots \cdots \cdots$ & $\nabla$ \\
\hline
\end{tabular}
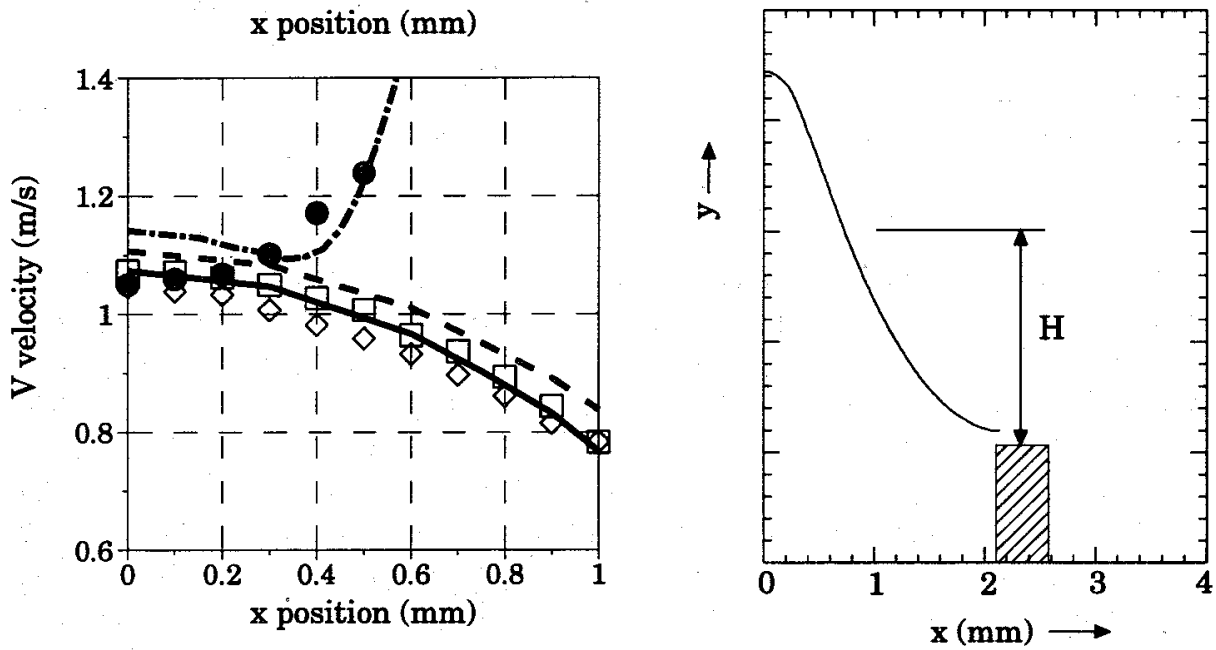

FIGURE 8 Comparison of the velocity component in $y$ direction predicted by the model (case $\mathrm{d} ; R_{0} \rightarrow \infty$ ) with LDV measurements.

of the diverging flow field in the lower part of the flame cone. This is in accordance with results for slit burners given by Lewis (1961). The divergent flow field in the lower part of the flame was not found by Echekki (1990) who performed Particle Tracking Velocimetry measurements in flames on slit burners. Echekki (1990), however, considered flames at much higher burner exit velocities (mean velocities of 1.5 to $2.5 \mathrm{~m} / \mathrm{s}$ ) whereas we consider much lower mean burner exit velocities $(0.8 \mathrm{~m} / \mathrm{s})$. Computations with our model have shown that the divergence of the flow field in the lower part of the flame is not present for higher inlet velocities.

\section{EFFECTS OF BURNER GEOMETRY AND SURROUNDING ATMOSPHERE}

The effects of burner curvature and confinement will be studied in this section. We will first discuss the differences in flame shape and mass flux through the flame tip between 
Bunsen flames on slit and tube burners surrounded by similar flames. The effects of confinement on the flame shape, the flow field and the mass flux $\rho v$ through the tip will be investigated subsequently.

The computation domain for the unconfined flames is given in Figure 3a; the domain for the confined flames is given Figure $3 \mathrm{~b}$. The domain measures are given in the Table II. The equivalence ratio $\phi=1.0[-], V_{\max }=1.2[\mathrm{~m} / \mathrm{s}]$ and $\Delta=0.3[\mathrm{~mm}]$ for all cases.

\section{Flames Confined Between Similar Flames}

The computed flame shapes of the flames confined between similar flames are given by the drawn lines in Figure 9. These lines represent the maximum locus of the chemical

TABLE II

The domain measures for the flames used in the investigation of the effects of the burner geometry and surrounding atmosphere (section 4)

\begin{tabular}{lrrrr}
\hline Confined & \multicolumn{2}{c}{ Yes } & \multicolumn{2}{c}{ No } \\
\hline$R_{0}$ & $\infty$ & 0 & $\infty$ & \multicolumn{1}{c}{0} \\
\hline$b[\mathrm{~mm}]$ & 2.1 & 2.1 & 2.1 & 2.1 \\
$B[\mathrm{~mm}]$ & 2.4 & 2.4 & 4.8 & 4.8 \\
$L_{x}[\mathrm{~mm}]$ & 2.4 & 2.4 & 15.0 & 9.0 \\
$L_{y}[\mathrm{~mm}]$ & 10.0 & 10.0 & 15.0 & 15.0 \\
\hline
\end{tabular}

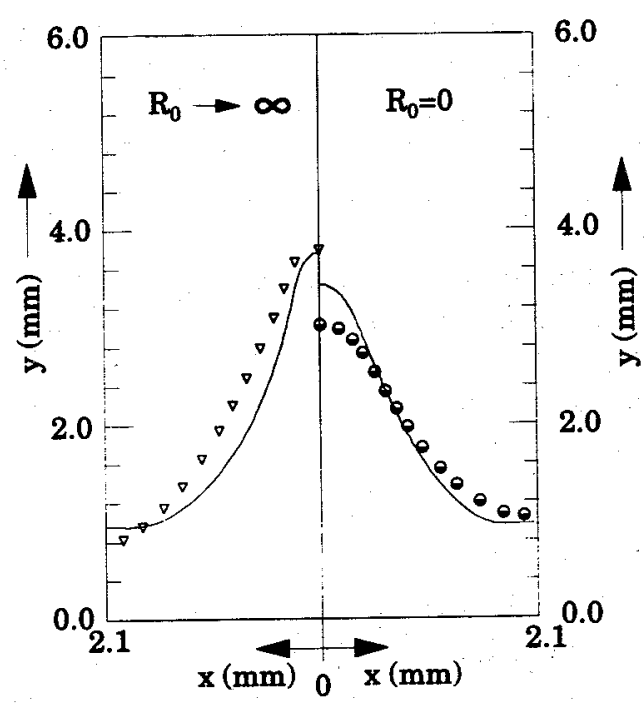

FIGURE 9 The shape of a Bunsen flame for $R_{0} \rightarrow \infty$ (left) and $R_{0}=0$ (right) enclosed within identical flames (lines) and with a surrounding atmosphere (markers). 
source term $\dot{\rho}_{f u}$ (in Eqn. (2)). There is a significant difference in flame length between the $R_{0} \rightarrow \infty$ case $(\approx 3.0 \mathrm{~mm})$ and $R_{0}=0$ case $(\approx 2.5 \mathrm{~mm})$. The cylindrical flame is shorter because this flame has more space to expand in radial direction. This can be shown by evaluating the radial term of the continuity equation: $1 / x \partial / \partial x(\rho u x)=\rho u / x+$ $\partial / \partial x(\rho u)=2 \partial / \partial x(\rho u)$ for $x \rightarrow 0$, which implies that the total mass flow rate in $x$ direction for the cylindrical case is twice as large as the mass flow in $x$ direction for a flame with $R_{0} \rightarrow \infty$, when the mass fluxes $\rho v$ are equal. This has important consequences for the flame stabilization and flame length. The large mass flow rate on the central axis $\rho V_{\max }$ in the upstream part of the flame has to decrease to values near $\rho^{u} s_{L}, s_{L}$ being the adiabatic burning velocity $(\approx 0.4 \mathrm{~m} / \mathrm{s}$ for a stoichiometric methane/air flame) at the flame tip to guarantee stable flame propagation in the tip (at $x=0)$. Note that this leads to values for $v$ at the tip which are almost an order of magnitude larger than $s_{L}$ (which is also reported by Echekki (1990)), because of the decrease of the density of the mixture. The surplus of mass has to be transported in $x$-direction through $\rho u$. It is easier to transport this mass away from the axis in the cylindrical case because of the larger expansion space. As a result, the flame tip on the multiple-slit geometry is longer and has a larger curvature to induce larger convective (and diffusive) transport in $x$-direction.

This phenomenon is increased further by the confinement of the flames. The modeled flow fields at $R_{0} \rightarrow \infty$ (de Lange, 1993) and $R_{0}=0$ show converging streamlines in the upstream part of the flame, especially near the tip. This convergence is caused by the restriction of the lateral expansion due to the symmetry boundaries at $x=B$. This is clearly visible in Figure 10, where the convective mass flux $\rho v$ along the centerline is shown for both geometries. The mass flux $\rho v$ in the upstream part of the flame increases less when $R_{0}=0$, again due to the larger expansion space in $x$ direction. The mass flux suddenly decreases to values close to the adiabatic mass burning rate near the flame front for stabilization reasons, as already mentioned.

Note that the final value of $\rho v$ at the flame tip is approximately equal to $0.6 \mathrm{~kg} / \mathrm{m}^{2} \mathrm{~s}$ for $R_{0} \rightarrow \infty$ and $\rho v \approx 0.5 \mathrm{~kg} / \mathrm{m}^{2} \mathrm{~s}$ for $R_{0}=0$ indicating that the burning velocity defined in the burnt mixture is roughly equal to $0.5 \mathrm{~m} / \mathrm{s}$ for the multiple-slit burner and $0.4 \mathrm{~m} / \mathrm{s}$ for the coaxial burner. The relatively large burning velocity of the $R_{0} \rightarrow \infty$ flame is caused by the larger curvature and stretch of the flame tip in combination with preferential diffusion effects.

Note also that the distance along the center line between the maximum mass flux $\rho v$ and the minimum value is considerably smaller for $R_{0}=0$ than for $R_{0} \rightarrow \infty$, implying that the flame thickness of the tip is smaller for $R_{0}=0$. This observation is related to the fact that the flame for $R_{0} \rightarrow \infty$ needs more time and space to dispose of the excess of mass on the central axis.

\section{The Effect of a Surrounding Atmosphere}

The influence of a surrounding atmosphere on the flame shape and the mass flux $\rho v$ through the tip is also of importance. The markers in Figure 9 represent the position of the numerical flame front of the flames with a surrounding atmosphere. The flames with the surrounding atmosphere are less curved, because the flow is lèss confined. This on its turn has consequences for the flame length. For $R_{0}=0$, the inclusion of a surround- 

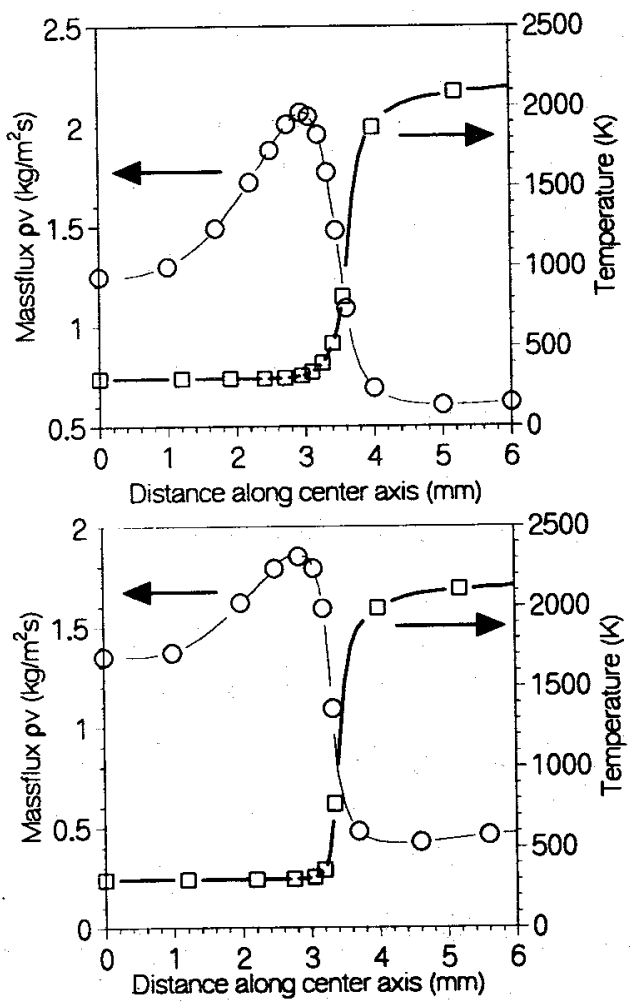

FIGURE 10 The mass flux $\rho v$ and the temperature at the centerline vs. the distance along the centerline for $R_{0} \rightarrow \infty$ (top) and $R_{0}=0$ (bottom) confined between symmetry boundaries.

ing atmosphere leads to a smaller flame length $(\approx 10 \%)$. The change in flame length for the slit burner is neglegible.

The mass flux $\rho v$ along the centerline for the cylindrical flame with a surrounding atmosphere is shown in Figure 11. The effect of the surrounding atmosphere on the mass flux $\rho v$ through the tip was similar for the $R_{0} \rightarrow \infty$ case. Instead of increasing, the mass flux now initially decreases in the lower part of the flame cone, because the stream lines near the centerline diverge slightly. This is also visible in direct photographs given by Lewis (1961). This diverging flow field is caused by the pressure drop over the sides of the flame (Poinsot, 1992) and the absence of confining (symmetry) walls near the flame. The flames now have less problems to get rid of the mass surplus on the central axis. Furthermore, the pressure drop over the tip is larger than the pressure drop over the sides of the flame (see e.g. Poinsot (1992)), which might cause the slight convergence of the flow field just ahead of the tip.

The result of these effects is that the mass flux just ahead of the flame tip is only $70 \%$ of the mass flux ahead of the flame tip confined between symmetry boundaries. Finally, the mass flux decreases rapidly in the flame front for stabilization reasons. Now the final mass flow rate is less than $\rho^{u} s_{L}$ due to the larger expansion in $x$-direction and the absence of confining walls. 


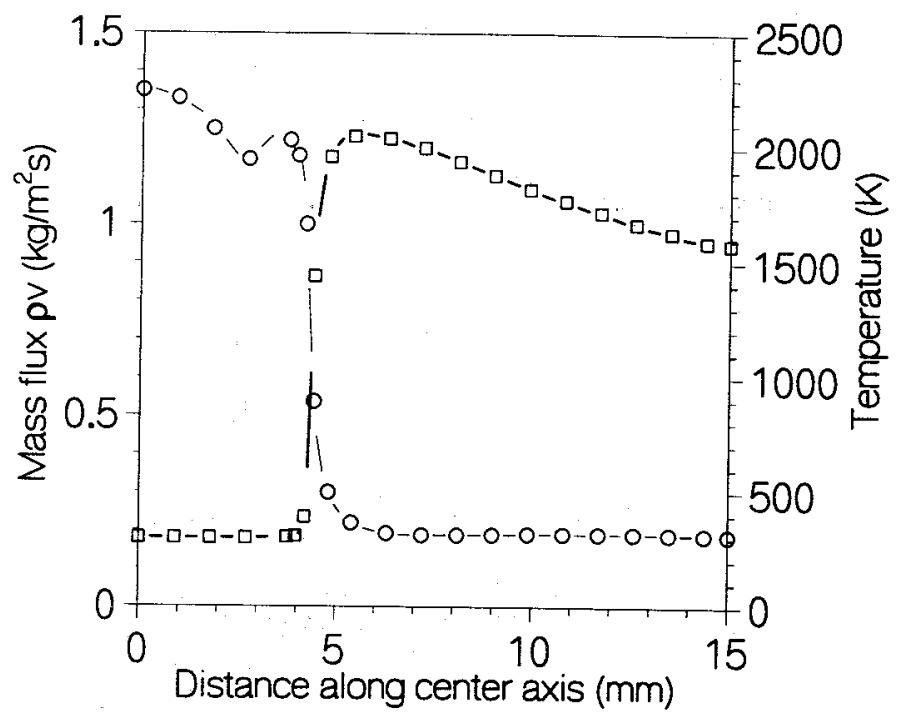

FIGURE 11 The mass flux $\rho v$ and the temperature at the centerline vs. the distance along the centerline for $R_{0}=0$ with a surrounding atmosphere.

The temperature after the tip of a cylindrical flame with a surrounding atmosphere (Fig. 11) decreases slowly which is caused by the cooling effect of the cold surrounding air. A smaller temperature decrease was found after the flame cone on a slot burner which is caused by the limited cooling effect of the cold surrounding gases and the limited length of the computational domain downstream of the flame.

\section{CONCLUSIONS}

Modeling results of laminar Bunsen flames burning in a cold surrounding atmosphere are presented. The 2D numerical model uses a one-step reaction and local grid refinements. The numerical model is validated with experiments. The global flow field and the flame shape of a flame on a tube burner in air has been compared with numerical results. It is shown that the flame shape and global flow field near the experimental flame is well reproduced by the model. Velocity profiles (measured with LDV) at various heights above the edge of a single-slit burner in an open atmosphere are compared with numerical data. The comparison shows that the model gives a good representation of the velocity field near the flame. The velocities given by the model differ no more than $10-15 \%$ from the measured velocities.

A numerical investigation of the effects of variations in burner curvature and the presence of a surrounding atmosphere on the flame shape and the mass flux through the tip has been carried out. The influence of curvature is studied by comparing flames with $R_{0}=0$ and $R_{0} \rightarrow \infty$, confined between other flames. The cylindrical flames are less 
curved, especially in the tip, and have a smaller mass flow rate on the central axis just ahead of the flame tip. These differences may be ascribed to the extra ability of the cylindrical flame to expand in radial direction. It has also been shown that a surrounding atmosphere has a significant effect on the flame shape, the mass flux through the flame tip and the curvature of the flame tip. The flames in an open environment can dispose of the excess of mass on the central axis more easily, due to the absence of confining objects near the burners. The investigations show that differences in expansion space near premixed Bunsen flames may lead to significant differences in flame shape, flow field and curvature.

\section{ACKNOWLEDGEMENTS}

The support of Gastec N.V. and NOVEM, the Netherlands, is gratefully acknowledged. H.B. Levinsky (N.V. Nederlandse Gasunie) is gratefully acknowledged for placing the direct photograph of the cylindrical Bunsen flame at our disposal.

\section{REFERENCES}

Andrews, G. E. and Bradley, D. (1972). The Burning Velocity of Methane-Air Mixtures, Combust. Flame 19, 275-288.

Coelho, P. J. and Pereira, J. C. J. (1993). Calculation of a Confined Axisymmetric Laminar Diffusion Flame Using a Local Grid Refinement Technique. Combust. Sci. and Tech., 92, 243-264.

Coffee, T. P.; Kotlar, A. J. and Miller M. S. (1984). The Overall Reaction Concept in Premixed, Laminar, Steady-State Flames. II. Initial Temperatures and Pressures. Combust. Flame, 58, 59-67.

Echekki, T. and Mungal, M. G. (1990). Flame Speed Measurements at the Tip of a Slot Burner: Effects of Flame Curvature and Hydrodynamic Stretch. Twenty-third Symposium (International) on Combustion, The Combustion Institute, Pittsburgh. pp. 455-461.

Fukutani, S. and Kunioshi, N. (1993). Stabilisation of Lean Methane-Air Premixed Flames. Fifth International Conference on Numerical Combustion, Garmisch-Partenkirchen. pp. 56.

Hertzberg, M. (1990). Flame Stretch Extinction in Flow Gradients, Flammability Limits Under Natural Convection. Twentieth Symposium (International) on Combustion, The Combustion Institute, Pittsburgh, pp. 1967-1974.

Kaskan, W. E. (1967). The Dependence of Flame Temperature on Mass Burning Velocity. Sixth Symposium (International) on Combustion, The Combustion Institute, Pittsburgh, pp. 134-143.

Lange H. C. de (1992). Modelling of Premixed Laminar Flames, Ph.D. Thesis, Endhoven University of Technology.

Lange, H. C. de and Goey, L. P. H. de (1993). Two-Dimensional Methane/Air Flame. Combust. Sci and Tech., 92, 423-427.

Lange, H. C. de and Goey, L. P. H. de (1994). Numerical Flow Modelling in a Locally Refined Grid. Int. J. Num. Meth. in Eng., 37, 497-515.

Lewis, B. and von Elbe, G. (1961). Combustion, Flames and Explosions of Gases. Academic Press, New York, Second Edition, pp. 267-281.

Maaren, A van, Thung, D. S. and Goey, L. P. H. de (1994). Measurement of Flame Temperature and Adiabatic Burning Velocity of Methane/Air Mixtures. Combust. Sci. and Tech., 96, 327-344.

Mungal, M. G. (1994). Instantaneous Velocity Measurements in Laminar and Turbulent Premixed Flames Using on-line PIV. Seventh International Symposium on Applications of Laser Techniques to Fluid Mechanics, Lisbon, pp. 15.1.1-15.1.7.

Poinsot, T., Echekki, T. and Mungal, M. G. (1992). A Study of the Laminar Flame Tip and Implications for Premixed Turbulent Combustion. Combust. Sci. and Tech., 81, 45-73.

Smooke, M. D., Mitchell, R. E. and Keyes, D. E. (1989). Numerical Solution of Two-Dimensional Axisymmetric Laminar Diffusion Flames. Combust. Sci. and Tech., 67, 85-122.

Wagner, T. C. and Ferguson, C. R. (1985). Bunsen Flame Hydrodynamics. Combust. Flame, 59, 267-272. Williams, F. A. (1988). Combustion Theory, Addison-Wesley Publishing Company, Menlo park.

Thiart, G. D. (1990). Improved Finite-Difference Scheme for the Solution of Convection-Diffusion Problems with the Simplen Algorithm. Num. Heat Transfer, part B 18, 81-95. 